\title{
Numerical Study of the Effects of Wave-Induced Forcing on Dynamics in Ocean Mixed Layer
}

\author{
Zengan Deng, ${ }^{1,2}$ Lian Xie, ${ }^{3}$ Ting Yu, ${ }^{2}$ Suixiang Shi, ${ }^{1,2}$ Jiye Jin, ${ }^{1,2}$ and Kejian $\mathrm{Wu}^{4}$ \\ ${ }^{1}$ Key Laboratory of Digital Ocean, State Oceanic Administration, Tianjin 300171, China \\ ${ }^{2}$ National Marine Data and Information Service, Tianjin 300171, China \\ ${ }^{3}$ Department of Marine, Earth and Atmospheric Sciences, North Carolina State University, Raleigh, NC 27695, USA \\ ${ }^{4}$ Ocean University of China, Qingdao 266100, China
}

Correspondence should be addressed to Zengan Deng; dengzengan@gmail.com

Received 7 March 2013; Revised 9 May 2013; Accepted 18 June 2013

Academic Editor: Bin Liu

Copyright (C) 2013 Zengan Deng et al. This is an open access article distributed under the Creative Commons Attribution License, which permits unrestricted use, distribution, and reproduction in any medium, provided the original work is properly cited.

\begin{abstract}
Numerical experiments using hybrid coordinate ocean model (HYCOM) are designed to quantify the effects of wind wave-induced Coriolis-Stokes forcing (CSF) on mixed layer (ML) dynamics in a global context. CSF calculated by the wave parameters simulated by using the WaveWatch III (WW3) model is introduced as a new driving force for HYCOM. The results show that noticeable influence on ocean circulation in ML can be caused by CSF. Over most of the global oceans the direction of Stokes transport is different from that of the change in current transport caused by CSF. This is not unusual because CSF is normal to Stokes drift. However, the CSF-caused change in current transport and the wave-induced Stokes transport have the same magnitude. The seasonal variabilities of mixed layer temperature (MLT) and mixed layer depth (MLD) caused by CSF are analyzed, and the possible relationship between them is also given.
\end{abstract}

\section{Introduction}

Ocean circulation is mainly driven by atmospheric forces through the ocean surface, for example, wind, heat, and fresh water. Wind blows at the ocean surface and produces gravity waves, transferring direct and indirect kinetic energies from atmosphere to ocean. Dynamics in the ocean surface mixed layer (ML) are influenced by the ocean surface waves mainly in three ways. First, wave breaking inputs turbulent kinetic energy (TKE) to turbulence. Second, the Langmuir circulations [1-5] resulting from the interaction of turbulent vorticity with wave-induced Stokes drift have their effect on turbulence in ML. Third, the Coriolis-Stokes forcing (hereinafter referred to as CSF), which is produced by interaction of largescale planet vorticity with Stokes drift and can be interpreted as a divergence of the wave-induced stress changes the ML dynamics by acting as a correction to the upper boundary condition [6-9]. In the upper ocean, wave breaking and the Langmuir circulation can be viewed as additional sources of TKE [5], whereas CSF acts as an additional forcing that changes the upper boundary conditions. In combination with the Coriolis forcing and the divergence of vertical momentum transfer by turbulent stress, CSF changes the Ekman balance in the wind-driven ML [7]. When considering the basin-scale circulation, McWilliams and Restrepo [10] proposed that effect of wave-driven current sometimes could be significant compared with the wind-driven counterpart. Polton et al. [8] argued that CSF dynamically influences the current profile throughout ML by changing the effective upper boundary conditions. The prominent impacts of CSF on upper ocean circulation in Taiwan Strait were investigated using a regional wave-current coupled model by Deng et al. [9]. Thus, there is necessity of CSF being included in global numerical ocean model if the physical integrity of surface-water motion is to be improved. In this work sensitive experiments are carried out using the Hybrid Coordinate Ocean Model (HYCOM) to estimate the effects of CSF on upper ocean dynamics within the mixed layer. The innovation of work is embodied in the implementation of wave-induced CSF in global ocean modeling and the improvement of the model physics. As 
will be shown in this study, including CSF will change the model's behavior in simulating current, temperature, and the depth of ML. In Section 2 we will introduce how to take CSF into account in HYCOM in detail. Then dynamics in ML with the presence of CSF will be discussed in Section 3 using sensitive experiments. The seasonal variability of mixed layer temperature (MLT) and mixed layer depth (MLD), as well as their possible relation, is analyzed. Validation and discussions are carried out in Section 4. Finally, the conclusions are summarized in Section 5.

\section{Implementation of CSF in HYCOM}

There is a mean Lagrangian volume transport produced in their propagation direction of monochromatic waves, the Stokes drift $\vec{u}_{s}[11]$, which can be expressed as

$$
\vec{u}_{s}=\vec{U}_{s} e^{2 k z}, \quad \vec{U}_{s}=c(a k)^{2} \cdot \vec{D},
$$

where $\vec{U}_{s}$ is the Stokes drift at the sea surface, $a$ is wave amplitude, $k$ is wave-number, $c$ is wave phase speed, $z$ is depth, that is, zero at the mean sea level and decreasing downward, and $\vec{D}$ is wave propagation direction. The interaction between the planetary vorticity and the Stokes drift yields $\operatorname{CSF}\left(\vec{f} \times \vec{u}_{s}\right)$ on the Eulerian momentum balance [6], where $\vec{f}$ is the Coriolis parameter. CSF can be interpreted as the divergence of a wave-induced stress $\vec{\tau}_{w}=\rho_{w} \cdot \overline{\widetilde{v} \widetilde{w}}$, which takes the form of

$$
-\rho_{w} \frac{\partial}{\partial z} \overline{\widetilde{v} \widetilde{w}}=-\rho_{w}\left|\vec{f} \times \vec{u}_{s}\right|,
$$

where $\rho_{w}$ is the sea water density and $\widetilde{v}$ and $\widetilde{w}$ are along wave crest component and vertical component of the rapidly varying wave orbital velocity, respectively.

2.1. Application of CSF in the Momentum Equation in the Ocean Surface Ekman Layer. In the classical Ekman layer model, the momentum equation describing the nonsteady state, ageostrophic current in the surface layer is $[9,12]$

$$
\begin{gathered}
\frac{\partial \vec{U}}{\partial t}+\vec{f} \times \vec{U}=\frac{\partial}{\partial z}\left(A_{z} \frac{\partial \vec{U}}{\partial z}\right), \\
\rho_{w} A_{z} \frac{\partial \vec{U}}{\partial z}=\vec{\tau}_{0} \quad z=0, \\
\vec{U} \longrightarrow 0 \quad z \longrightarrow-\infty
\end{gathered}
$$

where $\vec{U}$ is the horizontal current and $A_{z}$ is the vertical momentum diffusivity. Equation (4) is the corresponding boundary condition, in which $\vec{\tau}_{0}$ is the sea surface wind stress. $\vec{\tau}_{*}=A_{z}(\partial \vec{U} / \partial z)$ is turbulent stress. Introducing the wave-induced stress $\vec{\tau}_{w}$ into the vertical turbulent diffuse term, (3) can be rewritten as

$$
\frac{\partial \vec{U}}{\partial t}+\vec{f} \times \vec{U}=\frac{\partial}{\partial z}\left(\vec{\tau}_{*}+\vec{\tau}_{w}\right),
$$

where wave-induced stress is in the form of $\vec{\tau}_{w}=\rho_{w} \cdot \overline{\widetilde{v} \widetilde{w}}$. Incorporating (2) into (5) obtains

$$
\frac{\partial \vec{U}}{\partial t}+\vec{f} \times \vec{U}=\frac{\partial}{\partial z}\left(A_{z} \frac{\partial \vec{U}}{\partial z}\right)-\vec{f} \times \vec{u}_{s} .
$$

This equation is consistent with Polton et al.'s [8] statement that when the momentum equations are averaged over the wave periods, CSF appears as an extra term in the mean horizontal momentum equations that govern the ageostrophic motions. In this context, the Coriolis force-like CSF serves as a large-scale wave-induced forcing contributing to the vertical turbulent diffusion term [9].

2.2. Application of CSF in the HYCOM Momentum Equation. Integration of (2) from bottom to sea surface gives

$$
\vec{\tau}_{w}=-\rho_{w} f \times \vec{T}_{s}
$$

in which $\vec{\tau}_{w}$ is the depth-integrated CSF through the whole Stokes depth $\delta_{s}$ and $\vec{T}_{s}$ the depth-integrated wave-induced Stokes transport that can be expressed as

$$
\vec{T}_{s}=\int_{-\infty}^{0} \vec{u}_{s} d z=c(a k)^{2} \delta_{s} \cdot \vec{D}=\pi \frac{a^{2}}{T} \cdot \vec{D},
$$

where $T$ is the wave period. The Stokes drift $\vec{u}_{s}$ and CSF penetrate to a certain depth below the ocean surface, namely, Stokes depth $\left(\delta_{s}=1 / 2 k\right)$. Typically, the Stokes depth is about $5 \mathrm{~m}$ in the open ocean and is much shallower than winddriven Ekman layer depth [8].

Current field in the upper layer is of great interest to oceanography community. By analyzing the analytical solutions to the standard Ekman layer model which includes CSF, Polton et al. [8] and Wu and Liu [12] found that CSF does change the structure of the current profile, and this change stays within the Ekman layer. Thus, we assume that CSF is confined to the upper ocean ML. Here, the depthintegrated CSF is incorporated into the momentum equation of HYCOM [13] as a top boundary condition. Note that as a boundary condition, CSF does not always enhance the momentum input; it can also decrease the momentum input when wind and CSF having opposite directions. The K-profile parameterization (KPP; $[14,15])$ is employed as the mixing strategy. In the KPP mixing submodel, depth-integrated CSF is acting as a surface stress (equivalent wind stress), while the traditional KPP depends solely on wind forcing. To test the effects of CSF, here we keep all the tunable constants in KPP model at their default values. Incorporating CSF into the momentum equation of HYCOM in $(x, y, s)$ coordinates (where $s$ is an unspecified vertical coordinate) results in

$$
\begin{aligned}
\frac{\partial \vec{V}}{\partial t_{s}} & +\nabla_{s} \frac{\vec{V}^{2}}{2}+(\varsigma+f) \times \vec{V}+\left(\dot{s} \frac{\partial p}{\partial s}\right) \frac{\partial \vec{V}}{\partial p}+\nabla_{s} M-p \nabla_{s} \alpha \\
& =-g \frac{\partial \tau_{*}}{\partial p}+\left(\frac{\partial p}{\partial s}\right)^{-1} \nabla_{s} \cdot\left(v \frac{\partial p}{\partial s} \nabla_{s} \vec{V}\right),
\end{aligned}
$$


where $\vec{V}=(u, v)$ is the horizontal current velocity vector, $p$ is pressure, $\alpha=1 / \rho$ the potential specific volume, $\varsigma$ the relative vorticity, $M=g z+p \alpha$ the montgomery potential, $g z=\phi$ the geopotential, $f$ the Coriolis parameter, $v$ the eddy viscosity/diffusivity coefficient, and $\tau_{*}$ the shear stress vector induced by the combination of wind stress, bottom drag, and the depth-integrated CSF. $\dot{s} \partial p / \partial s$ represents the vertical mass flux across an $s$ surface. CSF influences the horizontal currents by changing both the shear stress and the eddy viscosity/diffusivity coefficient calculated in the KPP submodel. The function of CSF in both KPP submodel and momentum equation is reflected by changing the effective boundary conditions.

2.3. Dependences of the Thickness of Ocean Surface Boundary Layer and Mixed Layer on CSF. The ocean surface boundary layer depth (BLD) is calculated by the bulk Richardson number $\mathrm{Ri}_{b}$ through the KPP submodel of HYCOM [16], which takes the form of

$$
\mathrm{Ri}_{b}=\frac{\left(B_{r}-B\right) d}{\left(\bar{V}_{r}-\bar{V}\right)^{2}+V_{t}^{2}},
$$

with the unresolved turbulent velocity shear $V_{t}^{2}=$ $\left(C_{s}\left(-\beta_{T}\right)^{1 / 2} / \mathrm{Ri}_{c} \kappa^{2}\right)\left(c_{S} \varepsilon\right)^{-1 / 2} d N \omega_{s}$, where $\omega_{S}$ is the salinity/scalar turbulent velocity scale, which is defined as

$$
\begin{array}{r}
\omega_{S}=\kappa\left(a_{S} u_{*}^{3}+c_{S} \kappa \sigma \omega_{*}^{3}\right)^{1 / 3} \longrightarrow \kappa\left(c_{S} \kappa \sigma\right)^{1 / 3} \omega_{*} \\
\sigma<\varepsilon \\
\omega_{S}=\kappa\left(a_{S} u_{*}^{3}+c_{S} \kappa \varepsilon \omega_{*}^{3}\right)^{1 / 3} \longrightarrow \kappa\left(c_{S} \kappa \varepsilon\right)^{1 / 3} \omega_{*} \\
\varepsilon \leq \sigma<1 .
\end{array}
$$

In (11a) and (11b), $a_{S}$ and $c_{S}$ are constants, $\omega_{*}=\left(-B_{f} / h\right)^{1 / 3}$ is the convective velocity scale with $B_{f}$ representing the surface buoyancy flux, $\sigma$ equals $d / h_{b}$, and the friction velocity $u_{*}$ is estimated from the relation $u_{*}^{2}=|\tau| / \rho$, where $\tau$ includes surface wind stress and CSF. BLD is estimated as the minimum depth at which $\mathrm{Ri}_{b}$ exceeds the critical Richardson number $\mathrm{Ri}_{c}=0.3$. The calculation of surface BLD is based on $\mathrm{Ri}_{b}$, which is a function of $u_{*}$. BLD is therefore influenced by CSF, due to the dependency of $u_{*}$ on CSF.

In the KPP mixing strategy, estimation of MLD is diagnostically dependent on a temperature jump, for example, $0.3^{\circ} \mathrm{C}$. The bottom of the ML is set to an interpolated depth where the density jump is equivalent to the temperature jump. Usually, BLD and MLD are similar, since KPP mixes strongly down to BLD and density should be relatively homogeneous throughout the whole layer. BLD and MLD are determined by different criteria, the former is by buoyancy and the latter by temperature. Note that buoyancy and temperature can be linked through density. Thus, the effects of CSF on MLD are similar to those on BLD.
2.4. Dependence of Mixed Layer Temperature on CSF. The temperature conservation equation in HYCOM is given by

$$
\begin{gathered}
\frac{\partial}{\partial t_{s}}\left(\frac{\partial p}{\partial s} T\right)+\nabla_{s} \cdot\left(\vec{V} \frac{\partial p}{\partial s} T\right)+\frac{\partial}{\partial s}\left(\dot{s} \frac{\partial p}{\partial s} T\right) \\
=\nabla_{s} \cdot\left(v \frac{\partial p}{\partial s} \nabla_{s} T\right)+S_{T},
\end{gathered}
$$

for temperature $T$, eddy viscosity/diffusivity coefficient $v$, and the diabatic source terms that including diapycnal mixing, $S_{T}$. As presented in Section 2.2, CSF places itself into the momentum equation (6) as an extra source, thus affects horizontal current velocity $\vec{V}$. Since $\vec{V}$ plays its part in the second term of temperature conservation equation (12), CSF influences mixed layer temperature (MLT) indirectly. Additionally, CSF intensifies/weakens turbulent mixing in the upper ocean by modifying the diffusivity coefficient through acting on the KPP submodel as an effective top boundary condition. Thus in this context, we believe that the inclusion of CSF into numerical model also leads to the change of MLT.

\section{Effects of CSF on Dynamics in the Mixed Layer}

The connection between CSF and the dynamics in ML can be examined through diagnosing the responses of key variables based on numerical experiment. Exp. 1 and Exp. 2, without and with CSF, are, respectively, designed using HYCOM to assess the effects of CSF on upper ocean circulation, MLT and MLD.

3.1. Model Settings. CSF in this study is computed using the wave parameters generated by WaveWatch III (WW3), a third-generation wave model of wide application. WW3 is configured on a horizontal grid field from $90^{\circ} \mathrm{S}$ to $90^{\circ} \mathrm{N}$ and from $180^{\circ} \mathrm{W}$ to $180^{\circ} \mathrm{E}$, with a resolution of $2.5^{\circ}$ in both latitude and longitude, generating a total of $144 \times 73$ horizontal grid points. Input winds are from ECMWF ERA40 Reanalysis data sets. The first frequency is set at $0.0418 \mathrm{~Hz}$. With the frequency increment factor of 1.1, the number of frequencies is chosen to be 30 . The directional resolution is $15^{\circ}$. Minimum source term time step is $600 \mathrm{~s}$. Time interval of wind input is 86400 s. WW3 is spun up for 5 years, and then the 2001 actual year run is performed.

The configurations of HYCOM are mainly adopted from Deng et al. [17]. The calculation domain is from $64.43911^{\circ} \mathrm{S}$ to $64.43911^{\circ} \mathrm{N}$ with a resolution of $2.5^{\circ} \times \cos \varphi$ in latitude, where $\varphi$ is the corresponding latitude and $180^{\circ} \mathrm{W}$ to $180^{\circ} \mathrm{E}$ in longitude with a resolution of $2.5^{\circ}$. In vertical, 26 hybrid layers are set. Polar Science Center Hydrographic Climatology (PHC) 3.0 (available at http://psc.apl.washington.edu/nonwp_projects/ /PHC/Climatology.html) is used to initialize the model. This monthly climatology is also used for lateral boundary nudging and relaxation of salinity and temperature on the ocean surface. With forcing variables of $10 \mathrm{~m}$ winds, ocean 


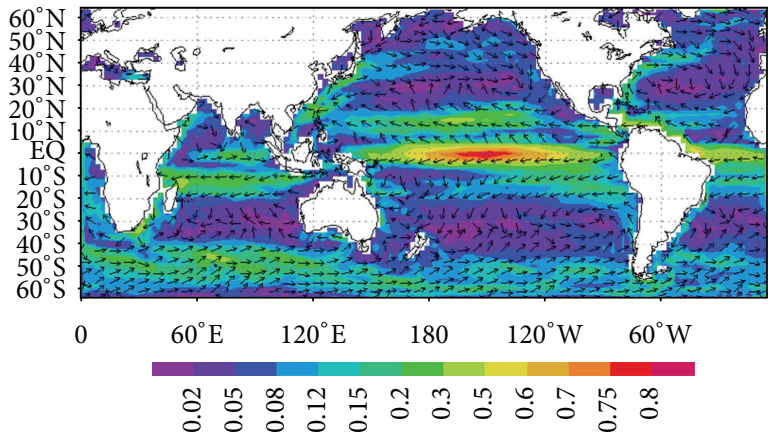

(a)

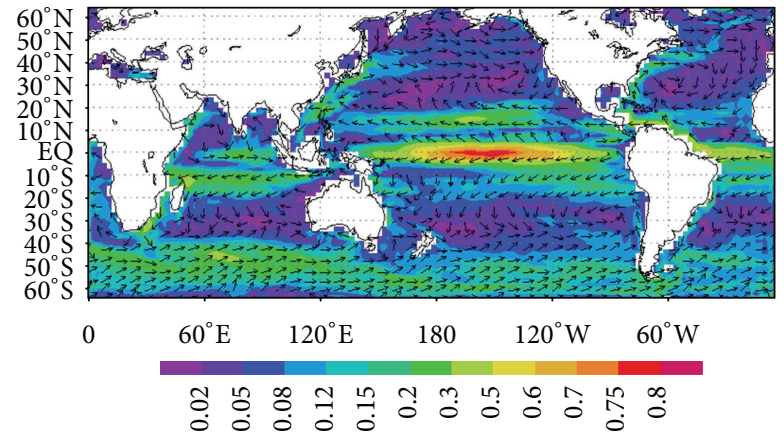

(b)

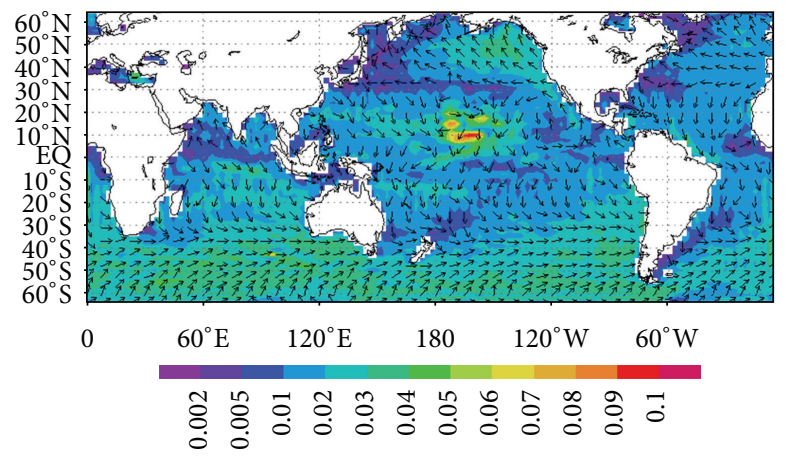

(c)

Figure 1: (a) Annual-mean mixed layer current field of 2001 from Exp. 1, in which CSF is not included as a top boundary condition; (b) annual-mean mixed layer current field of 2001 from Exp. 2, in which CSF is considered; (c) annual-mean changes (results of Exp. 2 minus that of Exp. 1) in mixed layer current. Currents $(\mathrm{m} / \mathrm{s})$ are vertically averaged through the mixed layer.

surface air temperature, precipitation, radiation heat flux, short-wave radiation, and water vapor mixing ratio from ERA15 ECMWF reanalysis monthly climatology, the model is spun up for 100 years. Then, 24-hourly ECMWF ERA40 wind anomalies are added to ECMWF ERA15 climatology to produce the 2001 actual year run.

3.2. Model Results. The starting point of examining CSF's effect here is to analyze the current field in ML. The net forcing on the sea surface with the presence of CSF will be increased (decreased) when CSF having the same (opposite) direction as that of wind stress. For example, in the equatorial Northeast Pacific, the generally northward Stokes drift induces an eastward CSF which is against the westward winds, resulting in the decreased net forcing.

The simulated global current fields in ML, derived respectively from Exp. 1 and Exp. 2, are shown in Figures 1(a) and 1(b). The South Equatorial Current, North Equatorial Current, and Equatorial Current are clearly shown. However, since the resolution $2.5^{\circ}$ is not fine enough to resolve the details of Western Boundary Currents such as the Kuroshio Current and the Gulf Stream, only their approximate locations are depicted. The CSF-induced changes of current speed over the global ocean are below $0.1 \mathrm{~m} / \mathrm{s}$ (Figure $1(\mathrm{c})$ ), with the large values appearing in the central tropical Pacific $\left(0^{\circ} \sim 20^{\circ} \mathrm{N}\right)$. This small range of speed change together with the similar current patterns in Figures 1(a) and 1(b) indicates that although the wave-induced CSF exerts an influence on the upper ocean circulation, especially over the westerly region, it cannot fundamentally change the structure of the current field.

Surface waves directly contribute to the volume transport in the upper layer, known as Stokes transport. We are wondering that through the action of CSF how much the variation of currents transport would be. As mentioned above the influence of surface wave is confined in the Ekman layer, here we compare the depth-integrated Stokes transport with the CSF-induced change in depth-integrated current transport in ML. The annual-mean depth-integrated Stokes transport $\vec{T}_{s}$ is calculated by the wave variables from the WW3 simulation and the ECMWF Reanalysis, respectively (Figures 2(a) and 2(b)). The general patterns of $\vec{T}_{s}$ in the two cases agree well; in particular the directions are quite similar over the circumpolar current regions, which partially indicates the reliability of the wave variables modeled by WW3. The magnitude differences between them are confined within $\sim 0.2 \mathrm{~m}^{2} \mathrm{~s}^{-1}$. At low latitudes, these differences are even smaller than $0.05 \mathrm{~m}^{2} \mathrm{~s}^{-1}$ (Figure 2(c)). The depthintegrated current transport in ML is expressed as $\vec{T}_{c}=$ $\int_{-d}^{0} \vec{V}_{z} d z$, where $\vec{V}_{z}$ is the current velocity and $d$ refers to the MLD. CSF-induced changes in depth-integrated current transport $\left(\Delta \vec{T}_{c}\right)$ are presented in Figure $2(\mathrm{~d}) \cdot \Delta \vec{T}_{c}$ generally 


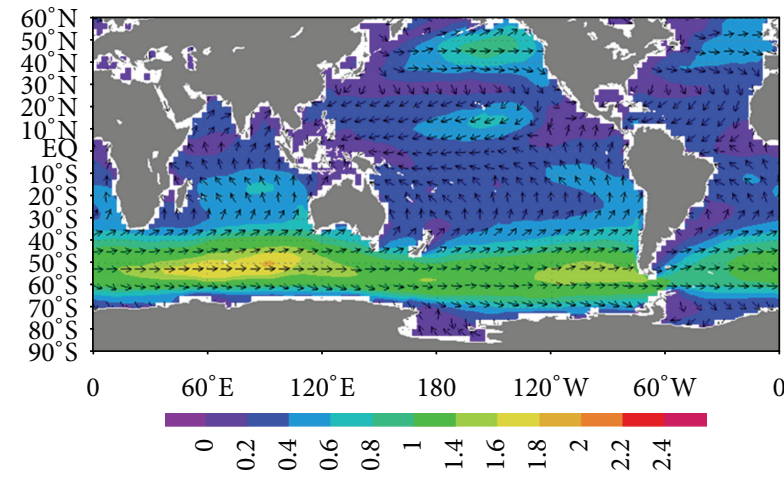

(a)

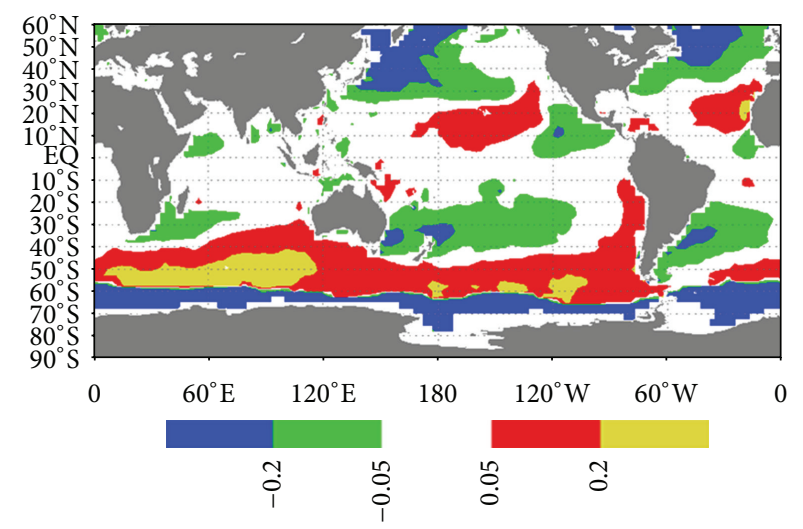

(c)

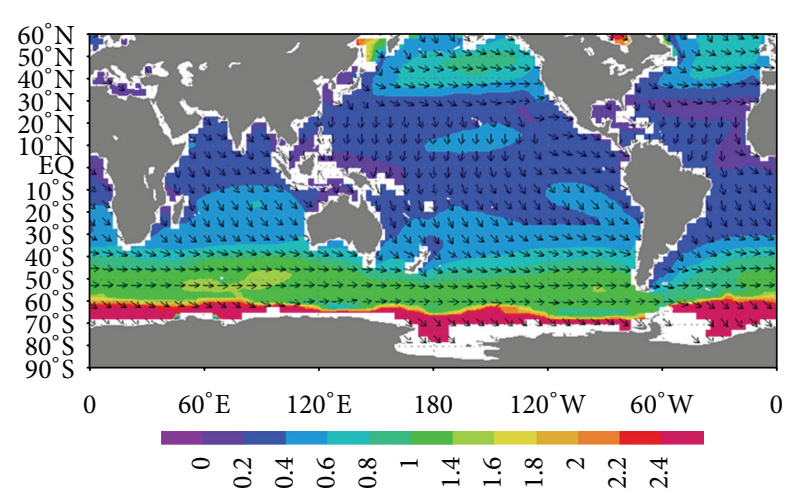

(b)

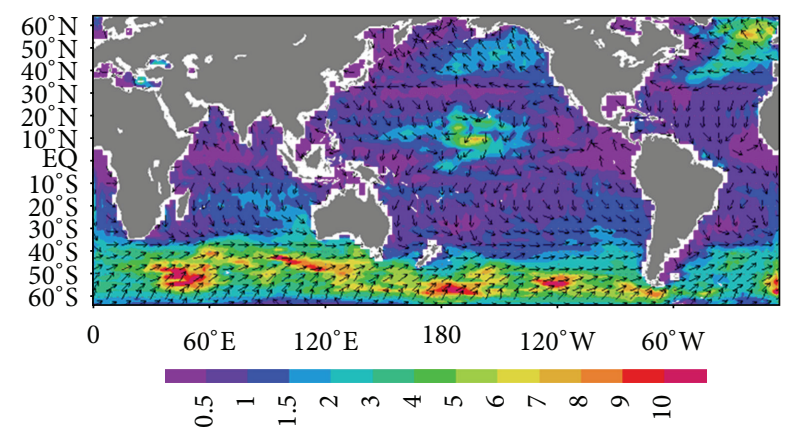

(d)

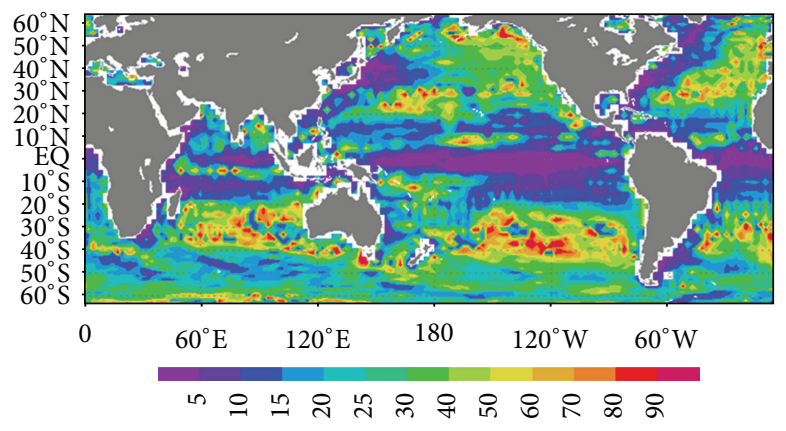

(e)

Figure 2: (a) Annual-mean depth-integrated wave-induced Stokes transport, $\vec{T}_{s}\left(\mathrm{~m}^{2} \mathrm{~s}^{-1}\right)$, simulated by WW3 model; (b) annual-mean depth-integrated wave-induced Stokes transport, $\vec{T}_{s}\left(\mathrm{~m}^{2} \mathrm{~s}^{-1}\right)$, calculated by ECMWF reanalysis wave variables; (c) the magnitude difference $\left(\mathrm{m}^{2} \mathrm{~s}^{-1}\right)$ between the WW3-based Stokes transport and ECWMF-based Stokes transport, with ECWMF-based $\vec{T}_{s}$ minus WW3-based $\vec{T}_{s}$; (d) annual-mean changes (results of Exp. 2 minus that of Exp. 1) in depth-integrated current transport through the mixed layer, $\Delta \vec{T}_{c}\left(\mathrm{~m}^{2} \mathrm{~s}^{-1}\right.$ ); (e) percentage change of $\vec{T}_{c}$, that is, $\Delta \vec{T}_{c} / \vec{T}_{c}$. Color indicates the magnitude and vector presents the direction.

ranges from 0 to $3 \mathrm{~m}^{2} \mathrm{~s}^{-1}$, with majority of the large values (maximum of $\sim 10 \mathrm{~m}^{2} \mathrm{~s}^{-1}$ ) occurring at westerly wind belt region, where relatively strong winds generate large waves. This result well verifies our hypothesis that when considering the effect of CSF on the ocean surface, wave-induced current transport in ML would be created. Furthermore, we notice that these changes are nontrivial; that is, the magnitude of $\Delta \vec{T}_{c}$ has the same order as that of $\vec{T}_{s}$. For better examining the response of current transport, Figure 2(e) gives the CSFcaused percentage changes in $\vec{T}_{c}$ (defined as $\Delta \vec{T}_{c} / \vec{T}_{c}$ ), upon which an effect of CSF on the upper ocean currents can clearly be found. Changes in tropical and Western Boundary Current regions are relatively small, about $10 \%$. Over the midlatitude region, especially those under the Westerlies, the changes are more than $30 \%$ (with the largest value reaching as high as $90 \%$ ), due to the strong wind waves acting on the currents 


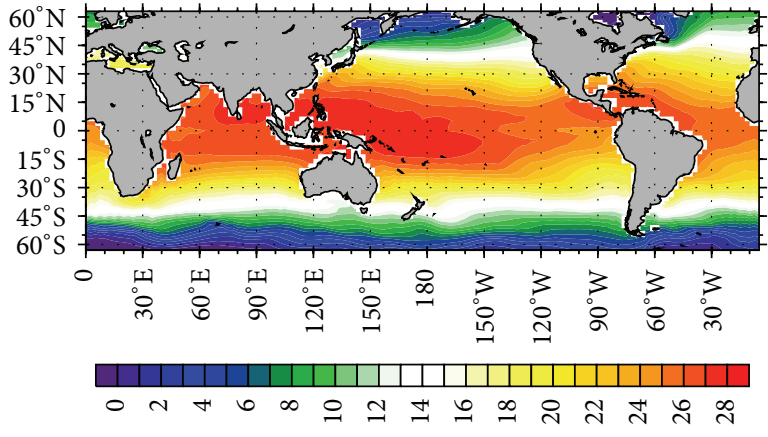

(a)

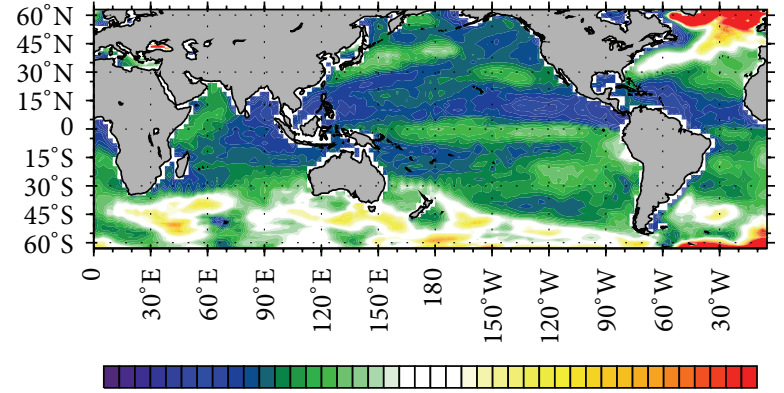

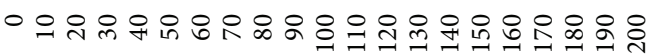

(b)

Figure 3: (a) Annual-mean temperature field in the mixed layer of 2001 from Exp. 1; (b) annual-mean mixed layer depth of 2001 from Exp. 1. Mixed layer depth here is defined as the depth that has a $0.3^{\circ} \mathrm{C}$ temperature jump to the sea surface temperature. Temperatures $\left({ }^{\circ} \mathrm{C}\right)$ are vertically averaged through the mixed layer.

there. In the ocean model, the ocean surface Ekman layer is usually characterized as an ocean surface boundary layer (BL). Given the fact that BL and ML usually have the same depth scale, the wave-induced percentage changes in $\vec{T}_{c}$ can be considered as a gauge of how important the wave-induced current transport is relative to the Ekman transport.

From Figures 2(a), 2(b), and 2(d), it is interesting to note that there are large differences between the directions of $\Delta \vec{T}_{c}$ and $\vec{T}_{s}$, except for the Circumpolar Current region (especially in the Pacific) where comparatively good agreement can be found. According to (7), the direction of CSF is perpendicular to that of the waves. Thus, as a response to CSF, the expected direction of $\Delta \vec{T}_{c}$ will be normal to that of $\vec{T}_{s}$. However, the model results suggest a different scenario. The direction of $\Delta \vec{T}_{c}$ is similar to that of $\vec{T}_{s}$ in southern westerly region where strong winds directly force large Stokes drift transport. In the eastern tropical region, the direction of $\Delta \vec{T}_{c}$ tends to be normal to that of the waves or $\vec{T}_{s}$ since the swell from remote areas dominates the wave field there [18], while at some other places, the directions of $\Delta \vec{T}_{c}$ and $\vec{T}_{s}$ are almost opposite, which can be explained as that the wave-induced Stokes transport $\vec{T}_{s}$ is compensated by the CSF to keep the balance of the global system. Theoretically, the direction of $\Delta \vec{T}_{c}$ over the southern and northern westerly regions should be symmetric since the CSF is equatorward at both of the two regions. As expected, between $40^{\circ} \mathrm{S}$ and $60^{\circ} \mathrm{S}$, the direction of $\Delta \vec{T}_{c}$ is generally equatorward, particularly in South Atlantic. However, the simulation in the northern westerly region is much more complicated. North of $40^{\circ} \mathrm{N}, \Delta \vec{T}_{c}$ are more likely to be northwestward, implying that poleward transport increases. Possible reasons for that could be the different topography and different wind wave intensity or other unclear influence over these regions. This phenomenon is worthy of further investigation. For the equatorial Pacific and Atlantic Oceans, $\Delta \vec{T}_{c}$ are southward, while in the Indian Oceans $\Delta \vec{T}_{c}$ have opposite directions between the North and South Hemispheres as if there were a boundary set at the equator.

The distribution of annual-mean MLT tends to be zonal (east-west), which is almost independent of longitude. The warmest water is near the equator (slightly higher than $29^{\circ} \mathrm{C}$ in the warm tongue), and the coldest water (about $-1.8^{\circ} \mathrm{C}$ ) locates close to the poles (Figure $3(\mathrm{a})$ ). As a wellmixed surface layer, ML can be rather thin in summer at low latitudes and much thicker in winter at middle to high latitudes. The annual-mean MLD over the global ocean (Figure 3(b)) varies from less than $10 \mathrm{~m}$ to more than $200 \mathrm{~m}$. It is generally less than $70 \mathrm{~m}$ in most of the region and more than $100 \mathrm{~m}$ at high latitudes. The patterns of ML circulation, MLT and MLD, from our simulation all agree well with the descriptions of Talley et al. [19]. The upper ocean ML connects the ocean to the atmosphere. Both MLT and MLD are critical factors in controlling the air-sea interactions thus the global climate. Many studies have found that there is a relationship between MLT and MLD (e.g., [20, 21]). Here we try to link the CSF-caused changes in MLD $(\Delta t h i)$ and MLT $(\Delta t e m)$ together to seek for their relationship and to find the possible reasons for the associated changes.

The annual and seasonal variabilities of $\Delta t e m$ and $\Delta t h i$ are analyzed (Figure 4). The annual-means $\Delta t e m$ and $\Delta t h i$ are approximately in the range from -1.2 to $1.2^{\circ} \mathrm{C}$ and -40 to $40 \mathrm{~m}$, respectively (top row of Figure 4 ). From the perspective of a year (in particular in summer and fall), the majority of the positive (negative) $\Delta t h i$ values correspond to the negative (positive) $\Delta$ tem values, possibly because that mixing intensified (weakened) by CSF generally decreases (increases) ocean surface temperature by entraining more (less) cold water into ML. However, at some places of Northern Hemisphere the increased $\Delta t e m$ are accompanied by the enhanced $\Delta t h i$ (e.g., the north subtropical Pacific in winter and spring). We assume that such case could be attributed to the increased turbulent mixing combined with the changed advection. For example, with more warm water travelling from the low latitudes to mid or high latitudes, the water temperature rises 

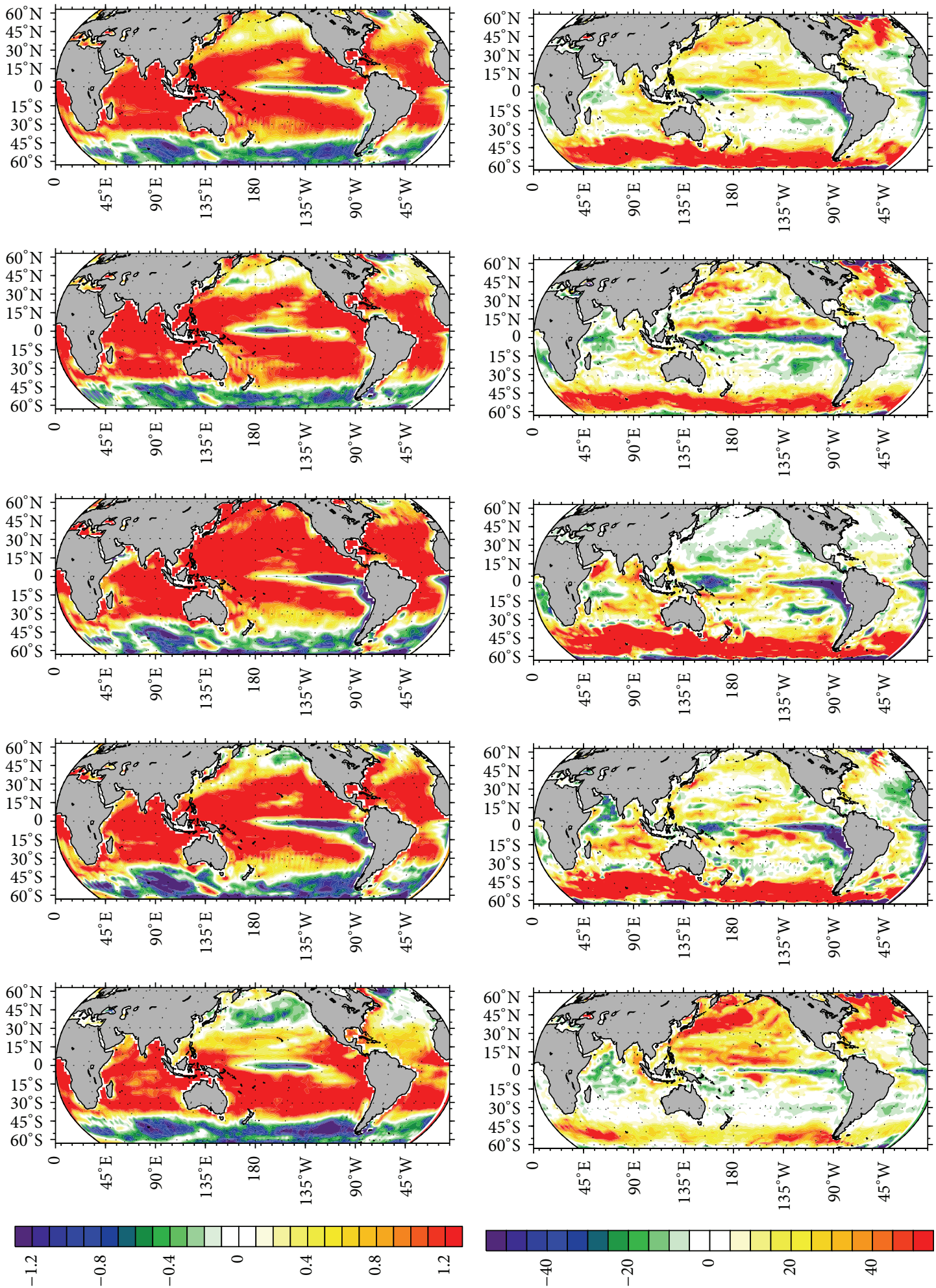

(a)

(b)

FIgURE 4: Changes in mixed layer temperature in ${ }^{\circ} \mathrm{C}$ (a) and changes in mixed layer depth in $\mathrm{m}$ (b) due to the inclusion of CSF into HYCOM. Plots from top to bottom, in order, respectively show the annual-mean, spring-mean (Mar May), summer-mean (Jun $\sim$ Aug), fall-mean (Sep Nov), and winter-mean (Dec $\sim$ Feb) results. 
locally at mid or high latitudes. This would compensate the temperature drop induced by deep water intrusion as a result of enhanced mixing. This phenomenon was also found by Carton et al. [21]. In the east equatorial Pacific and Atlantic both $\Delta t e m$ and $\Delta t h i$ are decreased (true for both annual- and seasonal-mean cases). Considering that those two regions are both swell dominated [18], the possible explanation for the decrease could be that swell-induced CSF weakens the local mixing and therefore decreases MLD; meanwhile the cold waters from high latitudes of the Southern Ocean carried by swell reduce MLT. There is an obvious reduction (enhancement) of MLT (MLD) in the southern westerly wind belt region for all seasons, which mainly due to the fact that the strong wind waves prevail in this region and CSF greatly intensifies the mixing in the upper ocean by interacting with the currents. For all seasons, at the low to middle latitudes of Southern Hemisphere (less than $35^{\circ} \mathrm{S}$ ), an increase of $\Delta t e m$ coincides with the decrease of $\Delta t h i$, which is a result of the decrease of net forcing. Above analysis indicates that the involvement of CSF as an upper boundary condition could have strong influence on the net forcing at the sea surface, leading to the seasonal variability of both $\Delta$ tem and $\Delta$ thi.

\section{Validation and Discussion}

As an important parameter that can be used to verify the capability of a numerical model in simulating the upper ocean phenomena, sea surface temperature (SST) can be directly measured with high accuracy by many marine instruments such as buoys. Observational array data of Tropical Atmosphere Ocean/Triangle Trans-Ocean Buoy Network (TAO/TRITON) are updated in real time and freely available to the research community. Here we use SST time series from TAO buoys which are deployed at the equatorial Pacific region to validate our simulation results. Figure 5 displays the comparisons of SST from model simulation and from TAO observations at 4 sites. These sites are located at $\left(0^{\circ} \mathrm{N}, 140^{\circ} \mathrm{W}\right),\left(0^{\circ} \mathrm{N}, 155^{\circ} \mathrm{W}\right),\left(5^{\circ} \mathrm{S}, 125^{\circ} \mathrm{W}\right)$, and $\left(10^{\circ} \mathrm{S}\right.$, $\left.10^{\circ} \mathrm{W}\right)$, respectively, covering the equatorial Pacific region sparsely. Considering no data assimilation is applied in our modeling, the deviations between the simulated SSTs and the observations are basically acceptable. All four cases show that, in general, the results with CSF are decreased and slightly closer to observations comparing to that without CSF. CSFinduced improvements in SST simulation can be appreciated in almost all seasons except spring, which proves that CSF is a necessary physics and is not negligible in upper ocean modeling. Kantha and Clayson [3] argued that the Langmuir cell-induced SST changes are well within the uncertainties in the modeled SST resulting from an imperfect knowledge of the air-sea fluxes used to drive the mixed layer models; thus it is hard to conclude that the simulated SST is substantially improved. Quantifying the improvements in the simulated SST as a result of including the effect of CSF is further complicated by errors associated with the imperfection of the mixed layer model. Nevertheless, it can also be found from Figure 5 that the CSF-resulted SST variations are quite pronounced during spring/summer periods (more than $1^{\circ} \mathrm{C}$ ) and are relatively small in fall and winter when ML is thicker. Such effects are comparable to the surface wave effects on ocean currents via the Langmuir cell and breaking waves [4].

\section{Conclusions}

The effects of wave-induced CSF on ML dynamics are numerically quantified using HYCOM. Typically, surfacewave-associated Stokes depth is about $5 \mathrm{~m}$ in the open ocean [8], while under the same condition the Ekman depth is much deeper (e.g., in $35^{\circ} \mathrm{N}$, under a wind speed of $10 \mathrm{~ms}^{-1}$, the Ekman depth is $\sim 120 \mathrm{~m}$ ). So, in the present analysis, we introduce the wave-induced CSF as a top boundary condition to modify the ML dynamics in the ocean circulation model. Serving as a correction to the upper ocean boundary conditions, CSF does not fundamentally change the structures of current field in ML. The change of current transport caused by $\operatorname{CSF}\left(\Delta \vec{T}_{c}\right)$ in $\mathrm{ML}$ ranges from 0 to $10 \mathrm{~m}^{2} \mathrm{~s}^{-1}$ and is comparable to wind-driven Ekman transport. Large values of $\Delta \vec{T}_{c}$ appear at areas under the westerly wind belt, since CSF caused by strong winds greatly enhances the turbulent mixing. The magnitude of depth-integrated Stokes transport $\vec{T}_{s}$ varies from 0 to $2.2 \mathrm{~m}^{2} \mathrm{~s}^{-1}$, in the same order as $\Delta \vec{T}_{c}$. However, except for the circumpolar current region, in most part of the global ocean the directions of $\vec{T}_{s}$ are different from that of $\Delta \vec{T}_{c}$. The spatial variability of $\Delta \vec{T}_{c}$ depends on the variation of the net forcing caused by CSF. The relationship between the changes in MLT $(\Delta t h i)$ and MLD $(\Delta t e m)$ caused by CSF has been quantified as well. Both of $\Delta t e m$ and $\Delta t h i$ have seasonal variability. The annual-mean values of $\Delta t h i$ are in the range from $-40 \mathrm{~m}$ to $40 \mathrm{~m}$ with obvious enhancements in the southern westerly region (particularly in summer and fall). The annual-mean values of $\Delta$ tem are from $-1.2^{\circ} \mathrm{C}$ to $1.2^{\circ} \mathrm{C}$. In most regions, especially the westerly region, CSF generally intensifies (reduces) the mixing in the ML and results in a decrease (an increase) in SST. In the equatorial region (particularly in the east equatorial Pacific), a decrease of MLT coincides with an increase in MLD. Sometimes at some places of Northern Hemisphere an increase in $\Delta$ tem is accompanied by an increase in $\Delta t h i$. This can be attributed to the increases in turbulent mixing combined with the changes in advection.

In conclusion, the wave-induced CSF has a noticeable influence on the dynamics in ML. This effect is more pronounced over the westerly region where strong wind waves are present. The comparisons of SST with some available TAO buoy observations show that the simulated SSTs are generally improved with the contribution of CSF. Therefore, inclusion of CSF into the global ocean model is a sound step toward better representing the real ocean surface processes. 


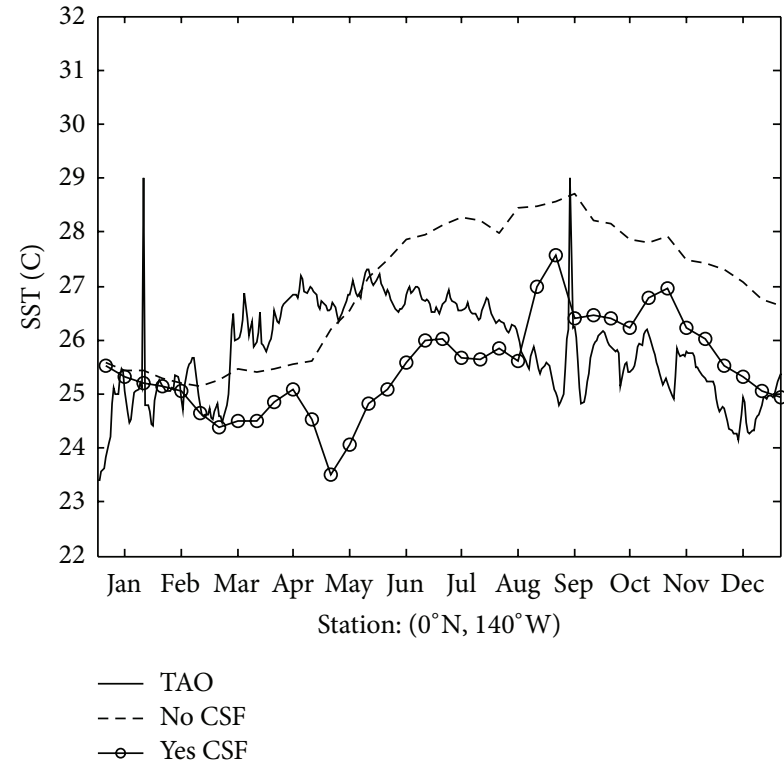

(a)

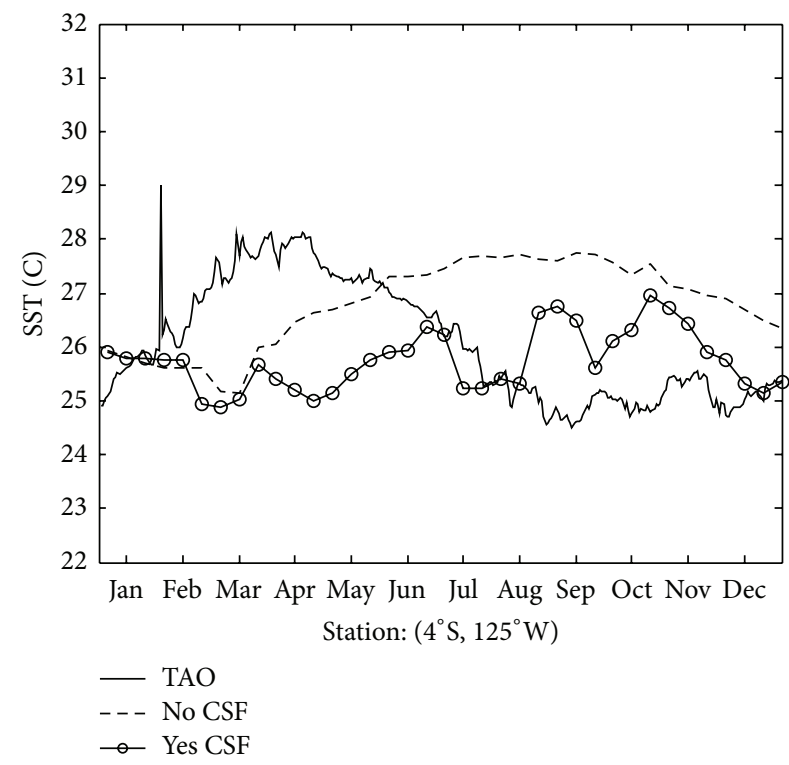

(c)

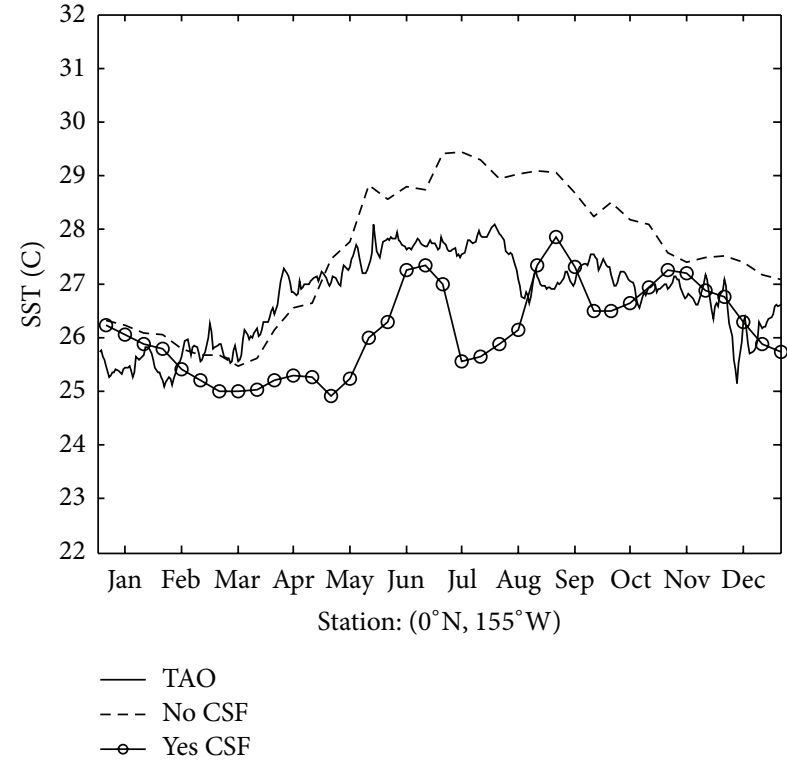

(b)

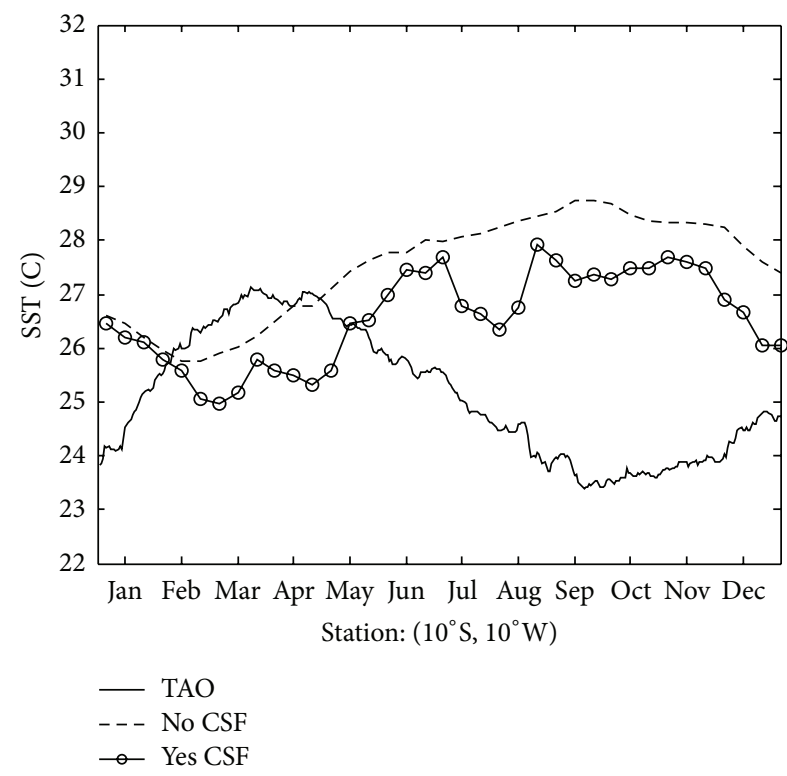

(d)

FIgURE 5: Daily SST $\left({ }^{\circ} \mathrm{C}\right)$ time series in 2001 from TAO buoys (solid line) and those output from HYCOM simulations with CSF (cycle line) and without CSF (dash line) for 4 stations at equatorial Pacific, $\left(0^{\circ} \mathrm{N}, 140^{\circ} \mathrm{W}\right),\left(0^{\circ} \mathrm{N}, 155^{\circ} \mathrm{W}\right),\left(5^{\circ} \mathrm{S}, 125^{\circ} \mathrm{W}\right)$, and $\left(10^{\circ} \mathrm{S}, 10^{\circ} \mathrm{W}\right)$.

\section{Acknowledgments}

This work is supported by the National Natural Science Foundation of China (nos. 41206012, 41171304), China 973 Program (2012CB316206), China 908 Program (Chinese Offshore Investigation and Assessment), and program for public from State Oceanic Administration, China (200905030). The discussion with Ms. Qi Dongmei and suggestions from anonymous reviewers contributed significantly to the present work. The Global Tropical Moored Buoy Array temperature observations were obtained from the TAO Project Office of NOAA/PMEL http://www.pmel.noaa.gov/tao/data deliv/ deliv.html.

\section{References}

[1] J. C. McWilliams, P. P. Sullivan, and C.-H. Moeng, "Langmuir turbulence in the ocean," Journal of Fluid Mechanics, vol. 334, pp. 1-30, 1997.

[2] M. A. C. Teixeira and S. E. Belcher, "On the distortion of turbulence by a progressive surface wave," Journal of Fluid Mechanics, vol. 458, pp. 229-267, 2002.

[3] L. H. Kantha and C. A. Clayson, "On the effect of surface gravity waves on mixing in the oceanic mixed layer," Ocean Modelling, vol. 6, no. 2, pp. 101-124, 2004.

[4] S. Carniel, M. Sclavo, L. H. Kantha, and C. A. Clayson, "Langmuir cells and mixing in the upper ocean," Nuovo Cimento della Societa Italiana di Fisica C, vol. 28, no. 1, pp. 33-54, 2005. 
[5] F. Ardhuin and A. D. Jenkins, "On the interaction of surface waves and upper ocean turbulence," Journal of Physical Oceanography, vol. 36, no. 3, pp. 551-557, 2006.

[6] K. Hasselmann, "Wave-driven inertial oscillations," Geophysical Fluid Dynamics, vol. 1, pp. 463-502, 1970.

[7] N. E. Huang, "On surface drift currents in the ocean," Journal of Fluid Mechanics, vol. 91, no. 1, pp. 191-208, 1979.

[8] J. A. Polton, D. M. Lewis, and S. E. Belcher, "The role of waveinduced Coriolis-Stokes forcing on the wind-driven mixed layer," Journal of Physical Oceanography, vol. 35, no. 4, pp. 444457, 2005.

[9] Z. Deng, L. Xie, G. Han, X. Zhang, and K. Wu, "The effects of Coriolis-Stokes forcing on upper ocean circulation in two-way coupled wave-current model," Chinese Journal of Oceanology and Limnology, vol. 30, no. 2, pp. 321-335, 2012.

[10] J. C. McWilliams and J. M. Restrepo, "The wave-driven ocean circulation," Journal of Physical Oceanography, vol. 29, no. 10, pp. 2523-2540, 1999.

[11] O. M. Philiips, The Dynamics of Upper Ocean, Cambridge University Press, 1977.

[12] K. Wu and B. Liu, "Stokes drift-induced and direct wind energy inputs into the Ekman layer within the Antarctic Circumpolar Current," Journal of Geophysical Research C, vol. 113, no. 10, Article ID C10002, 2008.

[13] R. Bleck, "An oceanic general circulation model framed in hybrid isopycnic-Cartesian coordinates," Ocean Modelling, vol. 4, no. 1, pp. 55-88, 2002.

[14] W. G. Large, J. C. McWilliams, and S. C. Doney, "Oceanic vertical mixing: a review and a model with a nonlocal boundary layer parameterization," Reviews of Geophysics, vol. 32, no. 4, pp. 363-403, 1994.

[15] W. G. Large, G. Danabasoglu, S. C. Doney, and J. C. Mcwilliams, "Sensitivity to surface forcing and boundary layer mixing in a global ocean model: annual-mean climatology," Journal of Physical Oceanography, vol. 27, no. 11, pp. 2418-2447, 1997.

[16] R. Bleck, G. Halliwell, A. Wallcraft, S. Carroll, K. Kelly, and K. Rushing, 2002, HYCOM User's Manual.

[17] Z. Deng, L. Xie, B. Liu, K. Wu, D. Zhao, and T. Yu, "Coupling winds to ocean surface currents over the global ocean," Ocean Modelling, vol. 29, no. 4, pp. 261-268, 2009.

[18] Z. Deng, K. Wu, D. Zhao, and T. Yu, "Effects of wind waves of the Pacific westerly on the eastern Pacific wave transport," Acta Oceanologica Sinica, vol. 28, no. 1, pp. 83-88, 2009.

[19] L. D. Talley, G. L. Pickard, W. J. Emery, and J. H. Swift, Descriptive Physical OceAnography: An Introduction, Academic Press, 2011.

[20] C. Deser, M. A. Alexander, and M. S. Timlin, "Understanding the persistence of sea surface temperature anomalies in midlatitudes," Journal of Climate, vol. 16, no. 1, pp. 57-72, 2003.

[21] J. A. Carton, S. A. Grodsky, and H. Liu, "Variability of the oceanic mixed layer, 1960-2004," Journal of Climate, vol. 21, no. 5, pp. 1029-1047, 2008. 

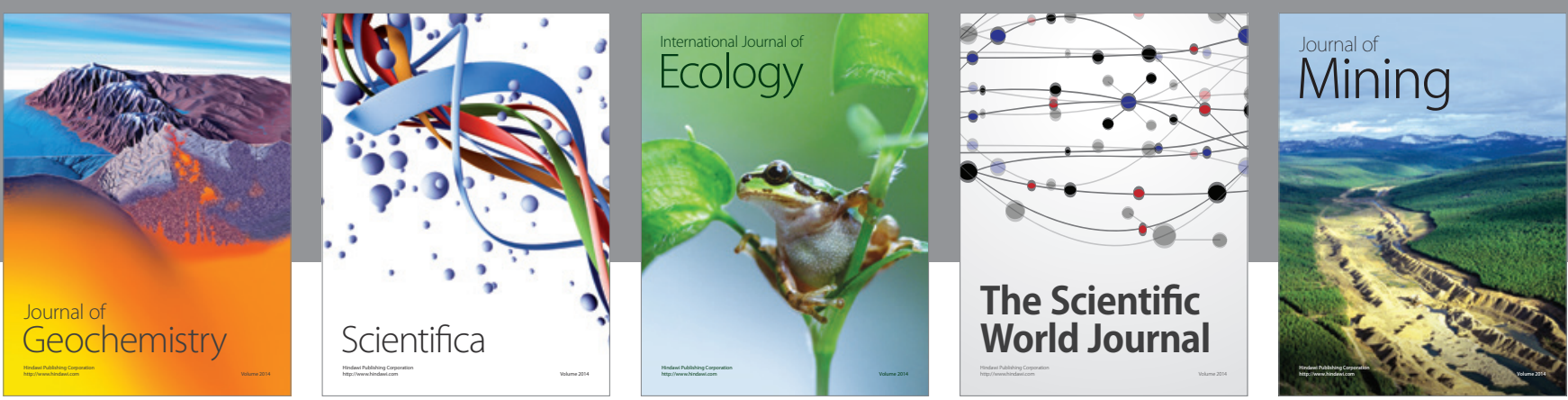

The Scientific World Journal
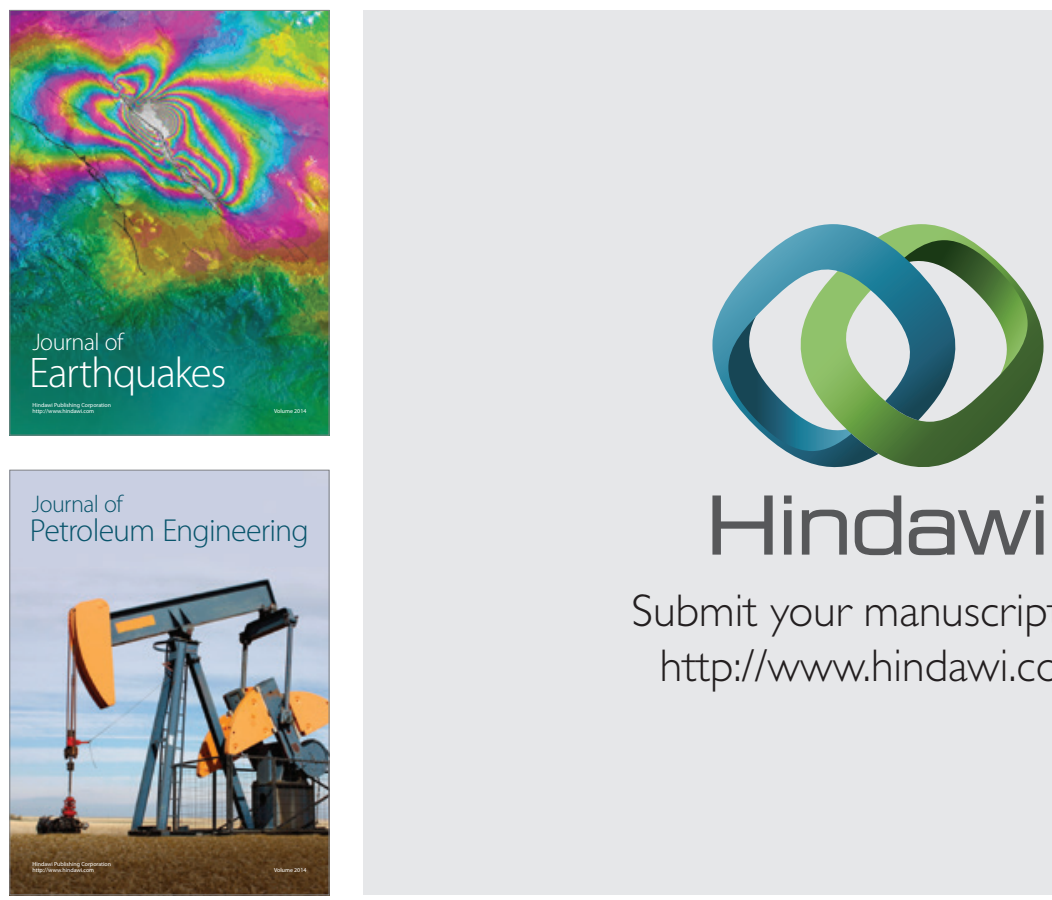

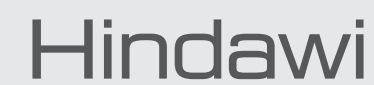

Submit your manuscripts at

http://www.hindawi.com
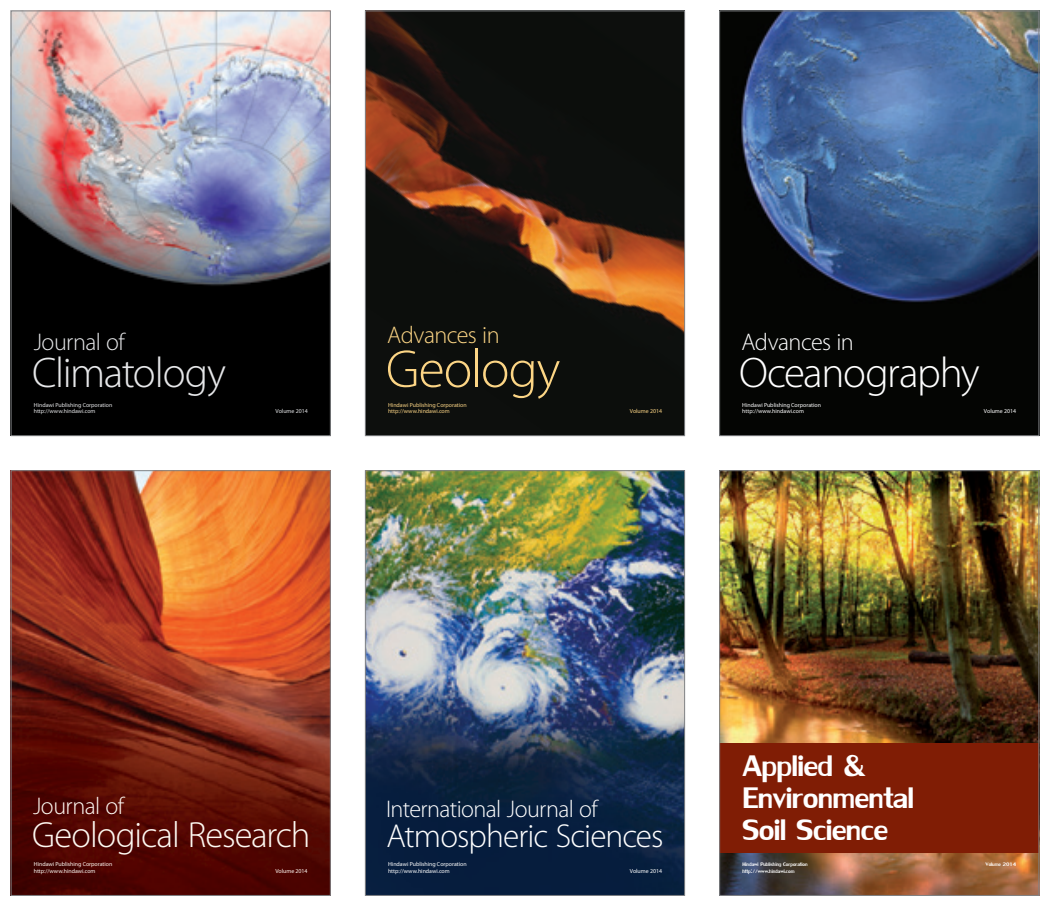
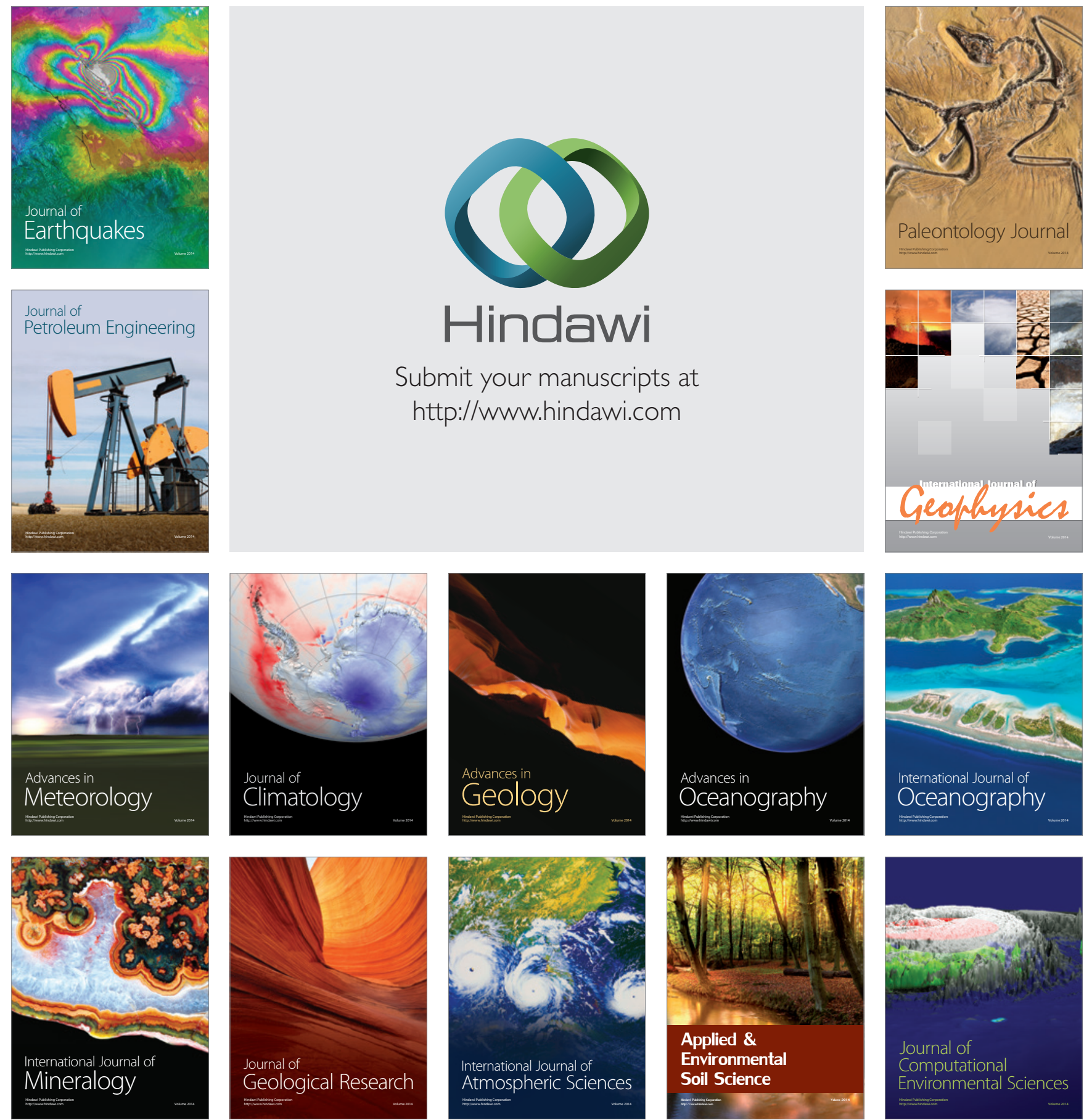